\title{
Setting the research agenda: strategic, research, and impact value of large-scale funded projects in Australasia
}

\author{
Glenda Anthony ${ }^{1}$ (D)
}

Received: 7 June 2017 / Accepted: 7 June 2017 /

Published online: 16 June 2017

(C) Mathematics Education Research Group of Australasia, Inc. 2017

The articles in this Special Issue Strategic research directions: Large-scale funded projects in Australasia collectively showcase a range of large-scale research projects sponsored by funding bodies in Australia, New Zealand, and Singapore-all key members of the MERGA community. Unusually for a research journal we have chosen to showcase these projects in the early stages as a way of communicating to the field what leading researchers and funders currently regard as significant and strategic research. Prompted by the unprecedented success rate of Australian mathematics education researchers in the 2016 Australian Research Council (ARC) Discovery Projects funding round we invited the six successful teams, along with researchers from the New Zealand and Singapore, to write about their projects.

Of course, we know that important research is conducted without funding - most notably the cutting edge contributions of doctoral studies and theoretical expositionsand acknowledge that many smaller funded project make significant contributions to the field. However, the projects featured in this issue represent a window into what research teams, policy makers, and government agencies collectively consider worthwhile in terms of national significance, innovation, and capacity building for field of mathematics education. For this reason, it is argued that the projects featured in this Special Issue represent in part the strategic directions for mathematics education research in Australasia. While authors of each article provide an overview of the aims, the theoretical and methodological frameworks, and expected contribution or their particular study, in this editorial I look at the collective contribution in terms of strategic value, research value, and impact value.

Glenda Anthony

g.j.anthony@massey.ac.nz

1 Massey University, Palmerston North, New Zealand 


\section{Strategic value}

To be of strategic value research needs to firstly address themes of strategic importance to mathematics education, either nationally or globally. While the nature of these themes is evolving, Lowrie (2015) notes that significant "community attention provides us with scope, capacity and opportunity not afforded to other fields of research in education" (p. 15). For educational systems within Australasia, it is without question that numeracy (and literacy), and capabilities in Science Technology, Engineering and Mathematics (STEM) currently receive considerably more political attention than other areas of learning in schools (English 2016). For mathematics education these areas of focus are tightly bounded to issues of equity within each of the three countries represented in this Special Issue. In Australia and New Zealand, despite considerable policy efforts and funded programmes, there remain significant concerns about the achievement outcomes and participation opportunities for Indigenous, Pasifika, and Māori students, and equity target groups in general (Hunter et al. 2016; Jorgensen 2014). Moreover, in a recent BBC report, Dr. Cheng (2017) noted that Singapore needs to heed the changing purpose of education "to ensure that Singapore can create a more equitable society, build a stronger social compact among its people while at the same time develop capabilities for the new digital economy". These concerns align with international trends. Indeed, the National Council of Teachers of Mathematics (NCTM) research committee's first draft of grand challenges for mathematics education identify "achieving equity in mathematics education" (Stephan et al. 2015, p. 139) as one of three themes.

Another area of strategic focus common among the three represented countries in this Special Issue is the attention to the teaching and learning processes that support success for learners. For mathematics education, this requires a focus on curriculum development and the need to teach higher level thinking skills and develop key competencies to prepare students for the twenty-first century. As noted in a UNESCO-funded report (Delors 1998), twenty-first century learning needs to be organised around four fundamental types of learning: Learning to know, learning to do, learning to live together, and learning to be. The focus on learning to be foregrounds "the development of learners' dispositions, capacities or competencies to deal with new situations and environments, including those with high degrees of complexity, fluidity and uncertainty" (Bolstad et al. 2012, p. 13). However, Jorgensen (2014) notes that while mathematics education research has recognised this focus through the precedence of social theories "there still remains the question as to how theorising the identities of learner will help advance mathematical learning for all students" claiming that what is lacking from most of the social theories "is the engagement with mathematical concepts and process" (p. 314).

For research to be of strategic value it must pose questions that will likely increase our knowledge and understanding about these strategic issues for education through the processes of consolidation, building, questioning, and identifying gaps in our knowledge. In looking across the eight featured projects the contribution to strategic value can be categorised as diverse, and importantly, in each case, future-focused. We have multiple projects that address curriculum issues related to twenty-first century learning. Most notably, at the secondary level, Geiger, Stillman, Brown, Galbraith, and Niss' project attends to the UNESCO pillars of learning through efforts to identify factors that 
enable Year 10/11 students to engage in the formation and mathematisation of real world problems. Building on a programmatic research base of designing modelling tasks, the project aims to get to the heart of understanding the processes of mathematisation - contributing to knowledge about the nature of anticipatory metacognition and enablers that promote mathematisation. In the New Zealand context, Yoon, Chin, Moala, and Choy are also engaged in a project that aims to understand more about the mathematical thinking processes related to mathematisation. In efforts to support teachers appreciate the value of mathematical modelling tasks this project seeks to explore ways to make the mathematical thinking process visible to students and teachers.

Projects on mathematical modelling align strongly to understanding and promoting mathematical activity that is relevant to twenty-first century learning. Other projects focused on learning in contemporary education settings include those of Chan, Clarke, and Cao and Makar and Fielding-Wells. Both of these projects are underpinned by the principle that social interaction is important for the promotion of learning in the mathematics classroom. In parallel investigations in Australia and China, involving purpose built research classroom environments, Chan et al.'s team aim to explore the learning processes involved in social interactions within small group problem solving activities. Their aim is to understand how we can optimise such social interactions for the promotion of learning in a mathematics classroom. Again, looking into existing classroom, this time through a video library resource, Makar and Fielding-Wells aim to explore how expert teachers and students co-develop and maintain classroom norms of mathematical inquiry.

Two projects offer exciting innovations in curriculum related to spatial reasoning. Lowrie and Jorgensen's and Mulligan, Woolcott, Mitchelmore, and Davis' projects both claim the centrality of spatial reasoning to mathematical competence and wider STEM disciplines. However, while both projects share a common aim of understanding more about the role of spatial reasoning in students' mathematical development their underpinning foci are quite distinct. In adopting an equity focus Lowrie and Jorgensen will look to uncover and understand the extent to which spatial work is implicated in "the construction of marginalisation and success for low SES and geographically disadvantaged students". In contrast, Mulligan et al., in adopting a curriculum and pedagogical focus, seek to challenge the way in which we structure or perceive the mathematics curriculum. In taking the innovative step to "spatialize the curriculum" they aim to disrupt the long-held curriculum (for primary schools) dominance of number concepts and arithmetic.

Achieving the goal of success for learners requires research focused on quality teaching and professional learning. Whilst all projects in this Special Issue include a professional learning component, the final two projects featured in this Special IssueChan, Clarke, Clarke, Roche, Cao, and Peter-Koop, and Kaur, Guan, Lam, Hoong, and Hoe - take teacher learning as a central concern, exploring the process of teacher knowledge construction in situ. Both projects are underpinned by the strategic importance of teacher learning and accountability (Anthony et al. 2016). Chan et al.'s proposed exploration of teachers' capacity to learn from everyday practices aligns with Kaur et al.'s examination of competent teacher practice. These studies aim to provide an evidenced-based data set to inform future curriculum and professional development models. 


\section{Research value}

The research value of funded projects can be expressed through multiple dimensionsincluding the nature of the questions as they relate to advances in the field, the innovation of the methodology, and the potential to promote research networking, partnerships, and capacity. It is of note that all of the featured projects involve large teams and in some cases these teams include international members and school partnerships. All projects involve multiple phases, conducted over sustained times periods, and sometimes across multiple sites. For example, Chan, Clarke and Cao's project on the social essentials of learning involves parallel studies in China and Australia. Each research site will utilise purpose designed classroom facilities with built-in videos cameras and audio recording equipment to enhance data collection.

Several of the projects feature innovative data analysis strategies that employ multiple theoretical frameworks. For example, Mulligan et al. intend to use social network analysis to inform the development of a documented knowledge framework that aligns with the Australian Curriculum-Mathematics and includes cross-curricular links that incorporate the components of the Spatial Reasoning Mathematics programme used in the intervention phase. Yoon et al.'s project plans to analyse transcripts of students' work on mathematising tasks using SPOT (Structure Perceived over Time) diagrams. These diagrams will highlight the "mathematical structures to which students attend, including mathematical objects, relations, attributes and operations". Across these projects these exploratory forms of analysis, development of new frameworks will undoubtedly serve to develop research capacity.

\section{Impact value}

What solutions and impact do these projects promise? In addition to the research and strategic values discussed above, the range of scope of the projects - addressing key areas of learning mathematics, curriculum and task development, teaching and professional learning - suggest collectively that the impact of these projects will be significant. Where projects, such as Mulligan et al.'s for example, build on an internationally recognised platform of research and include international team members there is a strong expectation that impact will be both national and international. Moreover, those projects that involve comparative and parallel data inputs from countries such as Germany and China (e.g., projects involving Chan and colleagues) provide unique opportunities to interrogate practices, theories and assumptions embedded in culturally defined education systems.

"Context is critical to, and in, educational research" (Lowrie 2015, p. 21) and in this regard it is noteworthy that all of the projects involve sustained exploration of learning and teaching in classrooms; a major impact goal being to directly improve our knowledge of effective teaching practices, curriculum enactment, and learner outcomes. In projects where efforts to ensure that teachers and students are consciously positioned as part of the knowledge generation the practice impact potential is significant. Interrogating and valuing the expertise of teachers in the field - as in Kaur et al.'s, Maker and Fielding-Wells' and Yoon et al.'s projects-will contribute to building better relationships and stronger links between research and practice. As Herbel-Eisenmann et al. (2016) note, 'in such a perspective, learning happens in both directions (p. 113). 
Overall, the MERGA community should feel enthusiastic about the strategic directions and potential impact of these projects as they develop over the coming years. However, in closing I wish to raise two important areas of focus that we as a community need to keep firmly within our horizon of attention. Firstly, English's (2016) commentary review from the latest Research in Mathematics Education in Australasia 2012-2015 warns that as a community we still face the challenge of "dealing with national and international assessments" (p. 366). We need to heed English's plea, striving to find ways to develop a more acceptable balance between the focus on our students' mathematics performance on these tests and the broader mathematical competencies as highlighted in many of these projects. If not, we risk the minimisation of impact of our efforts to develop sustained capacity in STEM education and twenty-first century skills. Secondly, and most importantly, it would be reassuring going forward if more of these projects could be explicit in their contribution to the grand challenge of equity (Stephan et al. 2015). Jorgensen and Lowrie, in combining their expertise in equity and spatial reasoning research, offer one way to do this. As Lowrie (2015) contends, our complex and interactive society demands "that we consider psychology, cultural differences and social justice dimensions with as much rigor and attention as mathematics content and processes" (p. 16). Thus, my hope is that projects that involve exploration of innovative opportunities to learn and teach mathematics will also serve to enhance our understanding about how to provide opportunities for all students to safely participate within their mathematics classroom in ways that increase their post-school and citizenship opportunities.

\section{References}

Anthony, G., Cooke, A., \& Muir, T. (2016). Challenges, reforms, and learning in initial teacher education. In K. Maker \& M. Goos (Eds.), Research in mathematics education in Australasia 2012-2015 (pp. 305327). Singapore: Springer.

Bolstad, R., Gilbert, J., McDowall, S., Bull, A., Boyd, S., \& Hipkins, R. (2012). Supporting future-oriented learning \& teaching: A New Zealand perspective. Wellington: Ministry of Education.

Cheng, L. L. (2017). Why high-flying Singapore wants more than grades. BBC News.

Delors, J. (Ed.). (1998). Education for the twenty-first century. Paris: United Nations Educational, Scientific and Cultural Organisation.

English, L. (2016). Advancing mathematics education within a STEM environment. In K. Maker \& M. Goos (Eds.), Research in mathematics education in Australasia 2012-2015 (pp. 353-371). Singapore: Springer.

Herbel-Eisenmann, B., Sinclair, N., Chval, K. B., Clements, D. H., Civil, M., Pape, S. J., et al. (2016). Positioning mathematics education researchers to influence storylines. Journal for Research in Mathematics Education, 47(2), 102-117.

Hunter, J., Hunter, R., Bills, T., Cheung, I., Hannant, B., Kritesh, K., \& Lachaiya, R. (2016). Developing equity for Pāsifika learners within a New Zealand context: Attending to culture and values. New Zealand Journal of Educational Studies, 51(2), 197-209.

Jorgensen, R. L. (2014). Social theories of learning: A need for a new paradigm in mathematics education. In J. Anderson, M. Cavanagh, \& A. Prescott (Eds.), Curriculum in focus: Research guided practice. (Proceedings of the 37th annual conference of the Mathematics Education Research Group of Australasia, pp. 311-318). Sydney: MERGA.

Lowrie, T. (2015). Mathematics education as a field of research: Have we become too comfortable? In M. Marshman, V. Geiger, \& A. Bennison (Eds.), Mathematics education in the margins (Proceedings of the 38th annual conference of the Mathematics Education Research Group of Australasia, pp. 14-24). Sunshine Coast: MERGA. 
Stephan, M., Fish, M., Chval, K., Herbel-Eisenmann, B., Wanko, J., Konold, C., et al. (2015). Grand challenges and opportunities in mathematics education research. Journal for Research in Mathematics Education, 46(2), 134-146. 